\title{
ADUBAÇÃO FOSFATADA NA SOJA DURANTE TRÊS SAFRAS CONSECUTIVAS NA NOVA FRONTEIRA AGRÍCOLA BRASILEIRA
}

\author{
Phosphate fertilization in soybean during three consecutive harvests in the new Brazilian agricultural frontier
}

Rubson da Costa Leite ${ }^{1}$, Jefferson Santana da Silva Carneiro², Gilson Araújo de Freitas ${ }^{3}$, Michel Elias Casali ${ }^{4}$, Rubens Ribeiro da Silva ${ }^{5}$

\author{
${ }^{1}$ Engenheiro Agrônomo, Mestrando, Universidade Federal do Tocantins-Campus Araguaína; E-mail: rubsonif@gmail.com \\ ²Engenheiro Agrônomo, Mestrando, Universidade Federal de Lavras; E-mail: carneirojss@yahoo.com.br \\ 3Doutor em Produção Vegetal, Universidade Federal do Tocantins-Campus Gurupi; E-mail: freitas@mail.uft.edu.br \\ ${ }^{4}$ Engenheiro Agrônomo, Mestre em Fitotecnia, Universidade Federal do Rio Grande do Sul; E-mail: \\ michel.casali@timacagro.com.br \\ 5Professor Adjunto da Universidade Federal do Tocantins-Campus Gurupi, Doutor em Solos e Nutrição de Plantas; E-mail: \\ rrs2002@uft.edu.br
}

Artigo enviado em 24/01/2017, aceito em 06/08/2017 e publicado em 20/12/2017.

Resumo: Compreendida pelo bioma Cerrado, a região do MATOPIBA, composta pelos estados do Maranhão, Tocantins, Piauí e Bahia, denominada a mais recente fronteira agrícola brasileira, é responsável por 11,96\% da área plantada com soja no país. Mediante a importância da fertilização fosfatada de solos com grande potencial agrícola para o país, o presente trabalho teve como objetivo avaliar o efeito de fertilizante fosfatado na soja durante três safras seguidas. O experimento foi realizado em área recém-aberta para produção de soja na fazenda Lazzari, no município de Formosa do Rio Preto-BA, nas safras 2013/2014, 2014/2015 e 2015/2016. O delineamento experimental foi em blocos casualizados, com cinco tratamentos e cinco repetições, através das doses de 0,100, 200, 300 e $400 \mathrm{~kg}^{-1} \mathrm{de}^{-1}$ $\mathrm{P}_{2} \mathrm{O}_{5}$ com fertilizante Top-Phos ${ }^{\circledR}$. Doses crescentes de adubação fosfatada tem influência positiva sobre os parâmetros altura de plantas, número de vagens por planta e produtividade em solo sob cerrado brasileiro. Em condições extremas de déficit hídrico, as plantas de soja respondem apenas para o parâmetro altura de plantas, não havendo influência dos outros parâmetros nessas condições.

Palavras-Chave - Glycine max. Top-Phos ${ }^{\circledR}$. Latossolos. MATOPIBA.

Abstract: Comprised of the Cerrado biome, the MATOPIBA region, comprising the states of Maranhão, Tocantins, Piauí and Bahia, the most recent Brazilian agricultural frontier, accounts for $11.96 \%$ of the area planted with soybeans in the country. Due to the importance of phosphatic fertilization of soils with great agricultural potential for the country, the objective of this work was to evaluate the effect of phosphate fertilizer on soybeans during three consecutive harvests. The experiment was carried out in a newly opened area for soybean production at the Lazzari farm, in the municipality of Formosa do Rio Preto-BA, in the seasons 2013/2014, 2014/2015 and 2015/2016. The experimental design was a randomized complete block design with five treatments and five replicates, using the doses of $0,100,200,300$ and $400 \mathrm{~kg} \mathrm{ha}^{-1}$ of $\mathrm{P}_{2} \mathrm{O}_{5}$ with Top-Phos ${ }^{\circledR}$ fertilizer. Increasing doses of phosphate fertilization had a positive influence on plant height, number of pods per plant and soil productivity under Brazilian cerrado. In extreme conditions of water deficit, the soybean plants responded only to the height parameter of plants, not having influence of the other parameters in these conditions.

Keywords - Glycine max. Top-Phos ${ }^{\circledR}$. Latosols. MATOPIBA.

\section{INTRODUÇÃO}

O Cerrado é o segundo maior bioma brasileiro, e é tido como a principal região agrícola do país, sendo a soja a principal cultura responsável pela expansão do agronegócio nessa região (ANDREA, ROMANELLI e MOLIN, 2016; COLOMBO et al., 2016).
Compreendida pelo bioma Cerrado, a região do MATOPIBA, composta pelos estados do Maranhão, Tocantins, Piauí e Bahia, denominada a mais recente fronteira agrícola brasileira, é responsável por 11,96\% da área plantada com soja no país (CONAB, 2017). Os Latossolos são os solos mais representativos na região, com grande potencial para a agricultura. Apresentam, no entanto, limitações sob o ponto de vista químico, como 
acidez, alta saturação de alumínio, baixa saturação de bases e baixa fertilidade natural, especialmente para o fósforo (P) disponível para as plantas (NETO et al, 2010; OLIVEIRA JÚNIOR; PROCHNOW e KLEPKER, 2011; REINA et al., 2014).

O P presente no solo encontra-se apenas parcialmente disponível para as plantas, pois ocorrem processos como formação de precipitados do $\mathrm{P}$ com cálcio em solo alcalino ou $\mathrm{Fe}$ e $\mathrm{Al}$ em solos ácidos (ZHOU et al., 2016), fixação em coloides minerais e por adsorção específica do $\mathrm{P}$ aos óxidos de $\mathrm{Fe}$ e $\mathrm{Al}$ (PELUCO et al., 2015), sendo este último fenômeno predominante em Latossolos do Cerrado brasileiro. Oliveira Junior, Prochnow e Klepker (2008), mencionam trabalhos em que $92 \%$ das amostras de solos coletadas em cerrado apresentaram teor de $\mathrm{P}$ disponível inferior a $2 \mathrm{mg} \mathrm{dm}^{-3}$.

O fósforo é um elemento essencial às plantas, de baixa solubilidade e mobilidade no solo, encontrando-se principalmente na forma de ortofosfato derivado do ácido fosfórico. Tem suprimento para as raízes efetuado principalmente pelo processo de difusão, o qual depende principalmente da interação com suas partículas, da umidade do solo e da superfície radicular (SILVA et al., 2014).

Com absorção pelas plantas nas formas de íons $\mathrm{H}_{2} \mathrm{PO}_{4}^{-}$e $\mathrm{HPO}_{4}^{-2}$, dependendo do valor do $\mathrm{pH}$ e após a absorção, apresentam grande capacidade em acumular esse fosfato. Esse nutriente tem importância para as plantas na constituição de compostos energéticos, como ATP, derivados do inositol (fitinas), fosfolipídios e outros ésteres, transferência de energia da célula, na respiração, fotossíntese, compõe a estrutura dos ácidos nucleicos de cromossomos e sua limitação pode provocar restrições no desenvolvimento (SILVA et al., 2014). É responsável pelo desenvolvimento adequado das raízes e das plântulas no início do seu desenvolvimento, contribuindo para o aumento da resistência aos estresses, na maior eficiência do uso da água, na resistência às doenças, além de estar muito relacionado à produtividade (MALAVOLTA, 2006; BEZERRA et al., 2014).

Mediante a importância da fertilização fosfatada e aos poucos trabalhos sobre o fósforo em solos com grande potencial agrícola para o país, o presente trabalho teve como objetivo avaliar o efeito de fertilizante fosfatado na soja na região do MATOPIBA.

\section{MATERIAL E MÉTODOS}

O trabalho foi realizado em parceria estabelecida entre a empresa TIMAC Agro/Zona Oeste, Fazenda Lazzari e Universidade Federal do Tocantins - Campus de Gurupi. A fazenda está localizada no município de Formosa do Rio Preto, no extremo Oeste da Bahia (11 ${ }^{\circ}$ 2' 19" Latitude Sul e 45 10'43" Longitude Oeste). O clima da região é do tipo Aw (ALVAREZ et al., 2013). A precipitação local é superior a $900 \mathrm{~mm}$ anual, concentrando-se nos meses de outubro a março e período de seca entre os meses de abril e setembro e a temperatura média é $24,3{ }^{\circ} \mathrm{C}$. O solo da área de cultivo apresenta textura franco arenosa (Tabela 1), sendo classificado como um Latossolo vermelho-amarelo (EMBRAPA, 2013).

Tabela 1. Caracterização química do solo (camada 0-20 cm) da área experimental localizada na região Oeste da Bahia. Formosa do Rio Preto-BA, 2013.

\begin{tabular}{|c|c|c|c|c|c|c|c|c|c|c|c|c|c|c|}
\hline $\mathrm{Ca}^{2+}$ & $\mathrm{Mg}^{2+}$ & $\mathrm{Al}^{3+}$ & $\mathrm{H}+\mathrm{Al}$ & $\mathrm{SB}^{(2)}$ & $\mathrm{CTC}^{(3)}$ & K & $\mathrm{P}$ & M.O'(1) & $\mathrm{pH}$ & Areia & Silte & Argila & $\mathrm{V} \%{ }^{(4)}$ & $\mathrm{m} \%$ \\
\hline & - & $-----C$ & $\mathrm{oll}_{\mathrm{c}} \mathrm{dm}^{-3}$ & 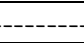 & ------- & $\mathrm{mg}$ & $\mathrm{lm}^{-3}$ & $\mathrm{~g} \mathrm{dm}^{-3}$ & $\mathrm{CaCl}_{2}$ & & $---(\%$ & ---- & & \\
\hline 1,89 & 1,84 & 0,0 & 1,34 & 3,25 & 4,59 & 5,22 & 11,25 & 14,2 & 6,29 & 69,51 & 7,39 & 23,11 & 70,58 & 0,00 \\
\hline
\end{tabular}

O experimento foi realizado em área recémaberta para produção de soja na fazenda Lazzari, implantado nas safras 2013/2014, 2014/2015 e 2015/2016. O delineamento experimental foi em blocos casualizados, com avaliação de cinco tratamentos e cinco repetições, através das doses de 0,100, 200, 300 e $400 \mathrm{~kg} \mathrm{ha}^{-1}$ de $\mathrm{P}_{2} \mathrm{O}_{5}$, com uso do fertilizante Top-Phos ${ }^{\circledR}$. Cada unidade experimental foi representada em $200 \mathrm{~m}^{2}$, totalizando $5000 \mathrm{~m}^{2}$ de área experimental. Utilizou-se o fertilizante Top-Phos ${ }^{\circledR}$, composto por: $0,1 \%$ de Nitrogênio; $22 \%$ de $\mathrm{P}_{2} \mathrm{O}_{5}$ solúvel em ácido cítrico; $28 \%$ de $\mathrm{P}_{2} \mathrm{O}_{5}$ total; $18 \%$ de $\mathrm{P}_{2} \mathrm{O}_{5}$ solúvel em água; $17 \%$ de $\mathrm{Ca}$ e $5 \%$ de $\mathrm{S}$.

O experimento foi cultivado com a soja M-SOY $9350^{\circledR}$, no espaçamento de $0,75 \mathrm{~m}$ entre linhas, com aproximadamente 15 plantas $\mathrm{m}^{-1}$, totalizando um stand de 200.000 plantas ha-1 . Anteriormente à implantação do experimento foi realizada uma adubação de correção com a aplicação de $\mathrm{KCl}$ e $\mathrm{P}_{2} \mathrm{O}_{5}$ de acordo com a análise de solo da área e exigências da cultura. A semeadura do primeiro ano de cultivo foi realizada dia 18 de novembro de 2013 juntamente com as doses referentes a cada tratamento. Os tratos culturais foram realizados segundo as recomendações para a cultura da soja no estado da Bahia, e foram realizadas adubações de cobertura com a utilização de $\mathrm{KCl}$, distribuído à lanço na fase V3 da cultura. Já na fase de florescimento da soja foram aplicados $\mathrm{Ca}$, B e Mn. Visando antecipar a colheita realizou-se a dessecação das plantas. A colheita foi realizada manualmente dia 10 de abril de 2014, colhendo-se as linhas centrais em cada parcela. 
$\mathrm{Na}$ segunda safra, a semeadura foi realizada dia 27 de novembro de 2014 utilizando semeadora mecanizada. Os tratos culturais e as adubações de cobertura foram realizadas de maneira semelhante a primeira safra, a colheita foi realizada manualmente dia 04 de maio de 2015, colhendo-se as linhas centrais de cada parcela.
Para a terceira safra, a semeadura ocorreu no dia 29 de novembro de 2015. Os tratos culturais e as adubações de cobertura semelhantes a primeira safra, e a colheita foi realizada manualmente dia 15 de abril de 2016. Foi realizado o acompanhamento das precipitações no município de Formosa do Rio Preto$\mathrm{BA}$, do plantio à colheita nas três safras no experimento (Figura 1).
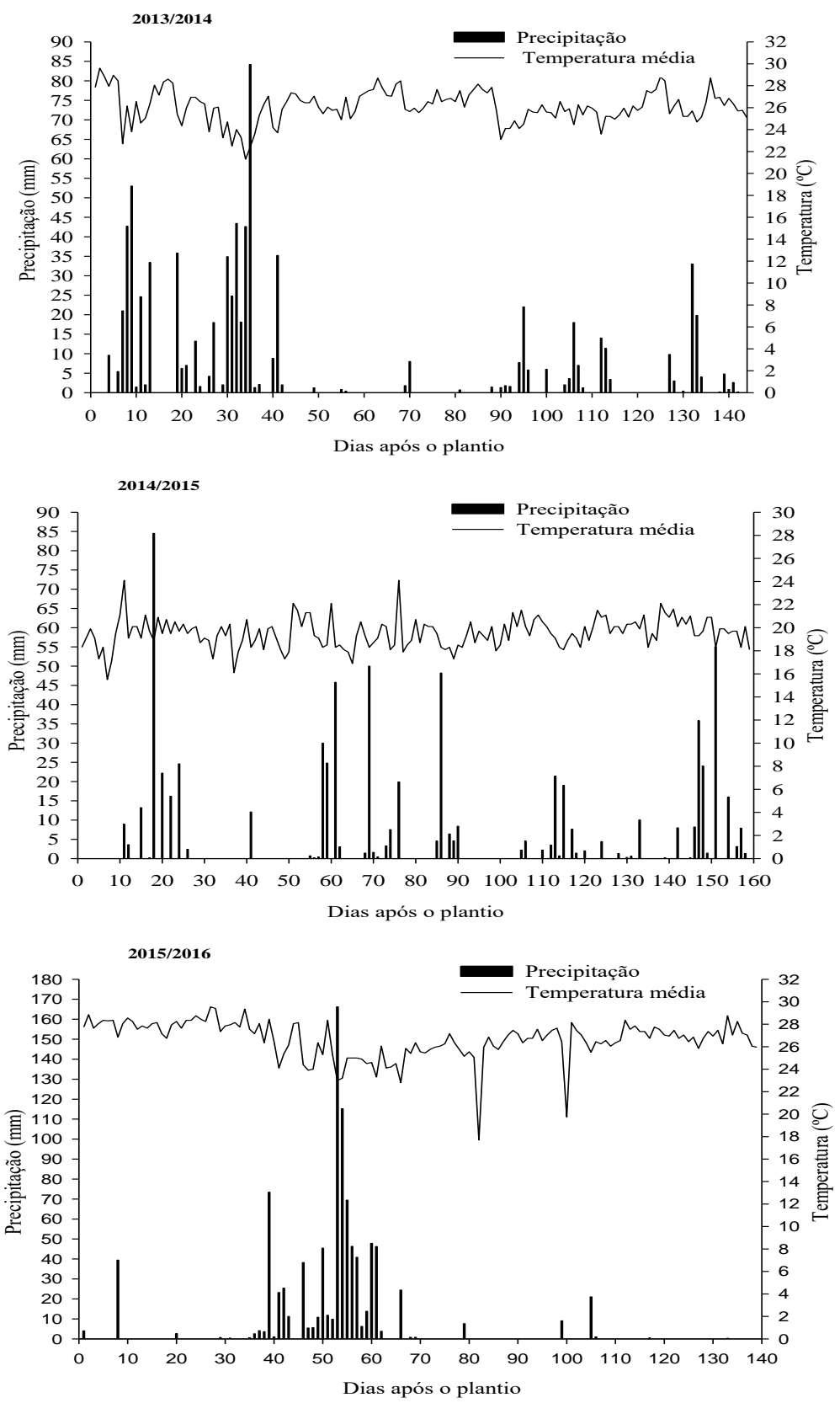

Figura 1: Temperatura e precipitação da área experimental nas safras 13/14, 14/15 e 15/16. Formosa do Rio-Preto - BA, 2016. 
Para avaliar o efeito das doses do fertilizante fosfatado nos indicadores de produção das plantas de soja foram usados os indicadores de produção: Altura de plantas (AP),determinada através da medição direta utilizando régua graduada em milímetros; Altura de inserção da primeira vagem (IPV), determinada através da medição direta utilizando régua graduada em milímetros; Número de vagens por planta (NV), determinada através da contagem desses indicadores nas plantas amostradas; Quantidade de grãos por vagem (GPV), determinada através da contagem desses indicadores nas plantas amostradas; Peso de mil grãos (PMG), com contagem de mil grãos e posterior pesagem em balança analítica; Produtividade (PRD), determinada com base na produção de grãos das plantas colhidas em cada parcela do experimento.

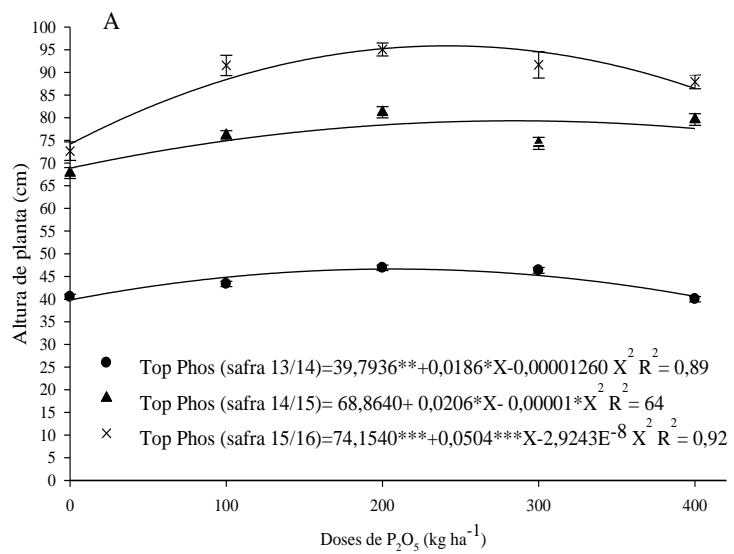

Os dados obtidos foram submetidos à análise de regressão, avaliando a significância dos betas e dos coeficientes de determinação para obtenção do modelo adequado à resposta das variáveis em função da dose de fertilizante. Os gráficos das regressões foram plotados utilizando o programa estatístico SigmaPlot versão $10^{\circledR}$.

\section{RESULTADOS E DISCUSSÃO}

$\mathrm{Na}$ avaliação da altura das plantas (AP) de soja, observou-se resposta quadrática, para todas as safras de avaliação do experimento em função de doses crescentes de fertilizante fosfatado (Figura 2A).

Figura 2: Altura de plantas (A) e Altura de inserção de primeira vagem (B) de plantas de soja em função de doses do fertilizante Top-Phos ${ }^{\circledR}$ nas safras 2013/2014, 2014/2015 e 2015/2016. Formosa do Rio Preto - BA, 2016.

Na safra 13/14, a AP encontrada com a dose de máxima eficiência $\left(206 \mathrm{~kg} \mathrm{ha}^{-1}\right)$ foi de $46 \mathrm{~cm}$. Já as plantas que não receberam dose de fertilizante fosfatado apresentaram em média $40 \mathrm{~cm}$ de altura. A baixa variação entre a altura de plantas que receberam e não doses de adubação fosfatado só foi possível devido a adubação de homogeneização realizada no início do experimento.

Para a safra $14 / 15$ na dose de máxima eficiência de $288 \mathrm{~kg} \mathrm{ha}^{-1}$ de $\mathrm{P}_{2} \mathrm{O}_{5}$ a AP foi de 79,46 cm enquanto a dose zero do fertilizante apresentou altura média de plantas de $67 \mathrm{~cm}$. Foi observado acréscimo expressivo na AP em comparação com a safra anterior, mesmo quando comparando a dose zero nas duas safras, evidenciando que a fertilização realizada anteriormente a implantação do experimento possibilitou elevado nível na AP porém pode ter limitado maiores resultados por não ter sido suficiente de acordo com o potencial genético da planta.

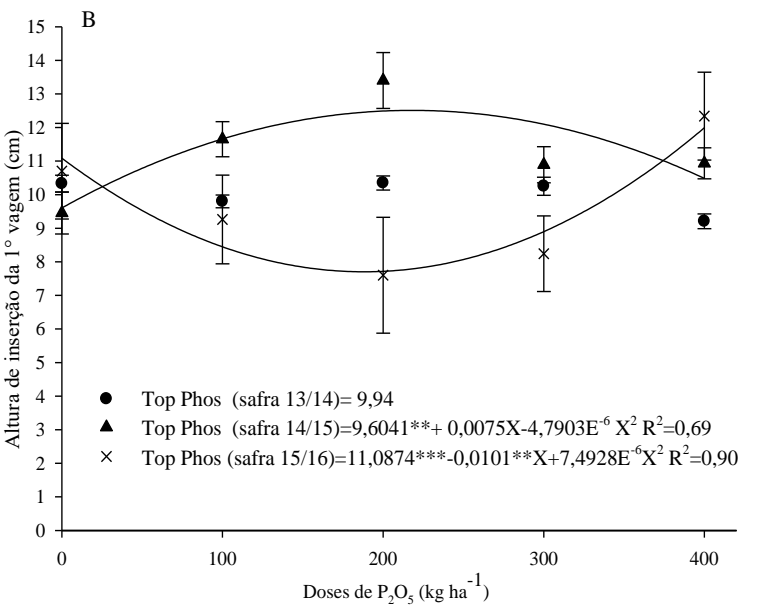

Na safra 15/16, foi verificada a dose máxima de eficiência de $241 \mathrm{~kg} \mathrm{ha}^{-1}$ do fertilizante fosfatado, que proporcionou altura máxima de plantas de $95,87 \mathrm{~cm}$. Isso representa um aumento de $32 \%$ em relação a dose zero do fertilizante e de $48 \%$ quando comparada a maior AP na safra 13/14. Essa maior altura de plantas está relacionada a fertilidade do solo que foi construída, com relação aos teores de $\mathrm{P}$, no decorrer das três safras de cultivo, visto que o fósforo deixado no solo na forma residual, pode ser uma fonte desse nutriente para a planta nos cultivos posteriores, resultando em maior disponibilidade de nutriente, produzindo plantas com maior altura. O aumento na AP é uma característica desejável, pois apresenta correlação positiva com a produtividade de grãos. Isto ocorre porque plantas bem nutridas e, consequentemente maiores, produzem maior número de estruturas reprodutivas (SCHONINGER et al., 2015).

O modelo encontrado no presente trabalho corrobora com Silva et al. (2015), que, avaliando 
cultivares de soja em função de adubação fosfatada no Oeste da Bahia, definiram o modelo de regressão quadrática para melhor representar a resposta de altura de plantas em função de doses crescentes de fertilizante fosfatado. Estes autores, utilizando a mesma cultivar de soja e fonte de fósforo deste trabalho, encontraram plantas de até $45 \mathrm{~cm}$ na melhor dose de $165 \mathrm{~kg} \mathrm{ha}^{-1}$ de $\mathrm{P}_{2} \mathrm{O}_{5}$.

De acordo com Bonfim-Silva et al. (2014), o fato das plantas apresentarem resposta positiva para altura com adubação fosfatada, reforça a essencialidade do fósforo no metabolismo das plantas desempenhando papel importante na transferência de energia da célula, na respiração e na fotossíntese. Desse modo, limitações na disponibilidade desse nutriente podem resultar em restrições no desenvolvimento da planta.

A altura de inserção de primeira vagem (AIPV) não apresentou ajuste à regressão para a safra $13 / 14$, demonstrando que essa variável não foi influenciada pelas diferentes doses de adubação fosfatada. Semelhante a Neto et al. (2010) que, avaliando diferentes níveis de adubação fosfatada na cultura da soja em cerrado piauiense, não encontraram interferência dos níveis de adubação sobre o parâmetro AIPV. Estes autores justificam que, mesmo o fósforo sendo exigido durante todo o ciclo da soja, a maior absorção desse nutriente ocorre após o florescimento, quando a AIPV já foi definida.

Para safra 14/15 a AIPV apresentou ajuste ao modelo quadrático, onde a dose de máxima eficiência (219 kg ha-1 de $\mathrm{P}_{2} \mathrm{O}_{5}$ ) apresentou plantas com AIPV de $11 \mathrm{~cm}$, a dose zero de fertilizante fosfatado apresentou plantas com altura de primeira vagem em média de 9,6 cm (Figura 2B). Neto et al. (2010), chamam atenção para influência da AIPV devido a relação com a colheita mecanizada de soja. Sediyama, Teixeira e Reis (2005), recomendam uma AIPV de 10 a $11 \mathrm{~cm}$ acima da superfície do solo para terrenos planos.

$\mathrm{Na}$ a safra 15/16, AIPV apresentou resposta quadrática inversa, não havendo na literatura explicação biológica para essa resposta no parâmetro avaliado, podendo ser essa resposta em função do erro experimental, que justifica a alta instabilidade dos valores componentes das médias para essa safra. A ausência de chuvas no período de florescimento pode ter influenciado nessa variável, visto que para a contagem de AIPV se dá a partir da primeira vagem cheia na planta.

Para número de vagens por planta (NVP), observou-se resposta linear crescente significativa na primeira e terceira safra e quadrática na segunda safra (Figura 3A).
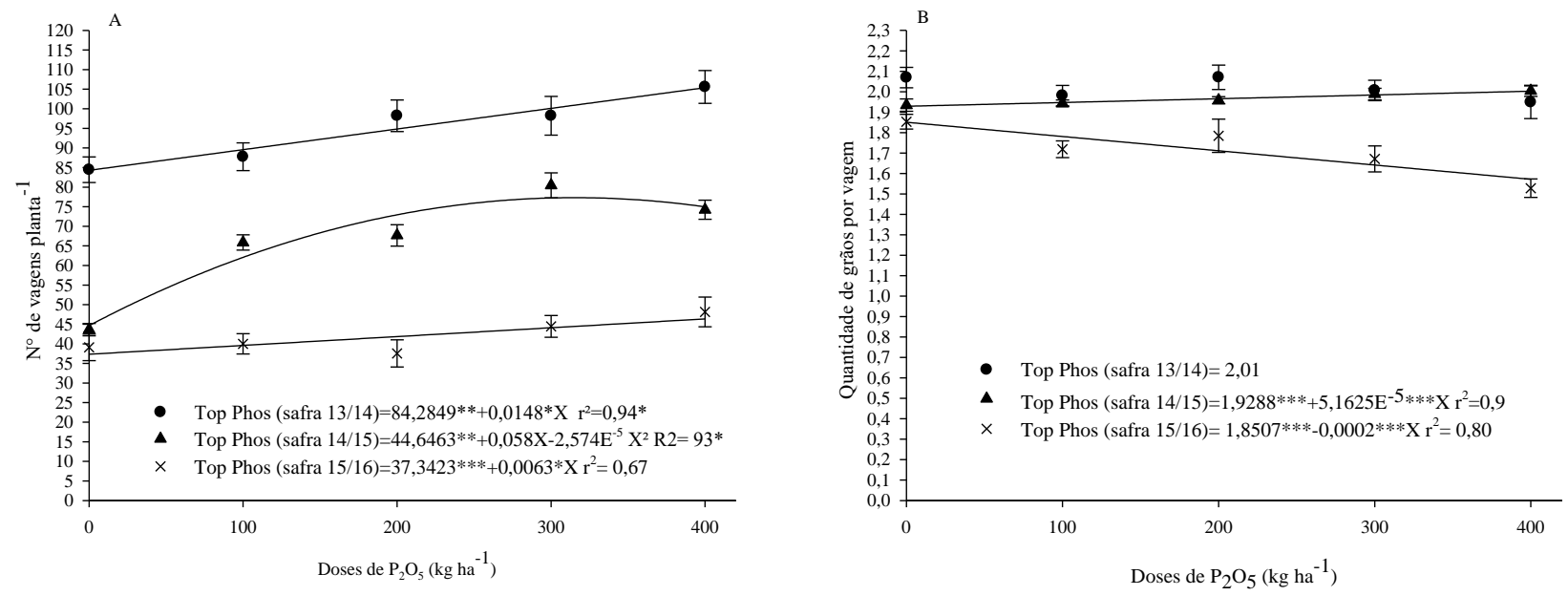

Figura 3: Número de vagens por planta (A) e Quantidade de grãos por vagens (B) de plantas de soja em função de doses do fertilizante Top-Phos ${ }^{\circledR}$ nas safras 2013/2014, 2014/2015 e 2015/2016. Formosa do Rio Preto - BA, 2016.

Na safra 13/14, com a aplicação de $400 \mathrm{~kg} \mathrm{ha}^{-1}$ de $\mathrm{P}_{2} \mathrm{O}_{5}$ foi obtido 105,36 vagens por planta, sendo resultado superior a safra $14 / 15$, na qual com a utilização da dosagem de máxima eficiência de $316 \mathrm{~kg} \mathrm{ha}^{-1}$ de $\mathrm{P}_{2} \mathrm{O}_{5}$, atingiu o número de 77,36 vagens por planta. Já para a safra 15/16, com a dosagem máxima de $400 \mathrm{~kg} \mathrm{ha}^{-1}$ de $\mathrm{P}_{2} \mathrm{O}_{5}$ foi obtida 48 vagens por planta. A redução do NVP com passar dos anos de condução do experimento, pode estar relacionado à quantidade e distribuição das chuvas na região, que ocasionou problemas nos estádios de florescimento e enchimento de grãos, sendo agravado na safra 15/16. Déficit hídrico expressivo durante a floração e o enchimento de grãos, provocam alterações fisiológicas na planta, como o fechamento estomático e o enrolamento das folhas e, como consequência causam a queda prematura das folhas e de flores e abortamento das vagens (EMBRAPA, 2011).

Nas três safras de cultivo no experimento foi possível observar a relação positiva do fertilizante fosfatado com a quantidade de vagens por planta. 
Quando comparadas as dosagens de máxima eficiência dos três anos de cultivo com os tratamentos que não receberam adubação fosfatada, obteve-se acréscimos de $24 \% 75 \%$ e $23 \%$, respectivamente, nas safras $13 / 14$, $14 / 15$ e $15 / 16$.

Silva et al. (2015), avaliando a resposta de plantas de soja em função da adubação com fertilizante fosfatado, encontraram maiores resultados com o uso de $400 \mathrm{~kg} \mathrm{ha}^{-1}$ de $\mathrm{P}_{2} \mathrm{O}_{5}$ para o NVP, semelhante a este trabalho (safras 13/14 e 15/16): o parâmetro avaliado por estes autores apresentou ajuste ao modelo de regressão linear positivo. Já Santos et al. (2015), avaliando a eficiência de fertilizante fosfatado sobre a soja no oeste da Bahia, encontraram ajuste ao modelo quadrático para NVP em função de doses de fósforo aplicados ao solo, corroborando com o modelo encontrado no presente trabalho para NVP na safra 14/15. Rosolem e Tavares (2006) mencionam a alta influência do $\mathrm{P}$ sobre o pegamento de vagens em plantas de soja, tendo esse nutriente influência direta sobre o NVP.

A quantidade de grãos por vagem (NGV) na safra 13/14 não apresentou ajuste ao modelo de regressão, demonstrando que não houve influência dos tratamentos sobre essa variável. Apresentou aumento linear em função das doses do fertilizante aplicado na safra 14/15, enquanto na safra 15/16 houve redução linear, porém, esses valores não foram considerados expressivos por sua baixa amplitude de variação (Figura 3B).

Na safra 14/15 houve uma variação de 0,07 grãos por vagem entre a maior e a menor dose, já na safra 15/16 apresentou uma variação de 0,33 grãos por vagem entre a maior e menor dose de fertilizante fosfatado. De acordo com Schoninger et al. (2015), essa é uma característica de alta herdabilidade genética e pouco influenciada pelo ambiente. Contudo, em situações ambientais altamente restritivas ao bom desenvolvimento da cultura, é possível haver alterações no NGV, em função das doses de P. Silva et al. (2015), também avaliando doses crescentes de fertilizante fosfatado no Oeste da Bahia, encontraram redução linear no número de grãos por vagem em função do aumento de doses de $\mathrm{P}_{2} \mathrm{O}_{5}$, porém destacaram a baixa amplitude de variação nos dados e inferiram que doses de fósforo não apresentaram influência sobre esse parâmetro.

Em relação ao peso de mil grãos (PMG), observou-se comportamento quadrático para a safra $13 / 14$, redução linear na safra $14 / 15$ e não houve ajuste para safra 15/16. (Figura 4A). O maior peso de mil grãos foi obtido no primeiro ano de cultivo com dose de 240 $\mathrm{kg} \mathrm{ha}{ }^{-1}$ de $\mathrm{P}_{2} \mathrm{O}_{5}$, obtendo $173,93 \mathrm{~g}$ em mil grãos, quando da dose zero de fertilizante fosfatado foi de $153 \mathrm{~g} \mathrm{em} \mathrm{mil}$ grãos, demonstrando a resposta positiva desse nutriente para a variável analisada. Esses resultados corroboram com Santos et al. (2015) e Silva et al. (2015) que, observaram resposta positiva do PMG na soja em função de doses crescentes de fósforo em solos do cerrado.

O evento de o PMG ter apresentado redução linear em função das doses crescentes de fertilizante fosfatado na safra $14 / 15$ pode ser relacionado ao fato de nos tratamentos com aplicação de fonte fosfatada as plantas de soja apresentaram maior quantidade de vagens por planta quando comparados a dose zero de fertilizante fosfatado, logo essas plantas tiveram a mesma quantidade de nutrientes, exceto o fósforo, para nutrir uma maior quantidade de estruturas reprodutivas. Rosolem e Tavares (2006), em seus trabalhos avaliando a deficiência de P na cultura da soja, mencionam o fato de as plantas com deficiência de $\mathrm{P}$ apesar de apresentarem menor quantidade de vagens, essas poucas vagens foram mais bem nutridas quando comparadas as plantas que tiveram o fornecimento adequado de P.

Pode-se se observar que o PMG apresentou valores inferiores na safra 15/16 quando em comparação as safras anteriores, fato que pode ser explicado pela baixa precipitação ao transcorrer dos anos de cultivo, durante a fase de floração e enchimento dos grãos (Figura 2). Segundo Rezende et al. (2005), apesar do fósforo ser exigido durante todo o ciclo da cultura, $60 \%$ é absorvido após o florescimento (estádio reprodutivo R1), assim, na safra 15/16, com a ocorrência de déficit hídrico no estádio mencionado, prejudicou a absorção pela planta do fósforo no solo.

Observou-se resposta quadrática para a produtividade de grãos nas safras 13/14 e 14/15 em função do uso do fertilizante fosfatado. Por outro lado, a safra 15/16 não apresentou ajuste aos modelos (Figura 4B). Na safra 13/14 com dose de $214 \mathrm{~kg} \mathrm{ha}^{-1}$ de $\mathrm{P}_{2} \mathrm{O}_{5}$ obteve-se produtividade de $2347 \mathrm{~kg} \mathrm{ha}^{-1}$, enquanto que com a ausência do fertilizante obteve-se $1818 \mathrm{~kg} \mathrm{ha}{ }^{-1}$, representado acréscimo de $29 \%$. Para safra 14/15, a maior resposta em produtividade foi obtida utilizando a dose de $224 \mathrm{~kg} \mathrm{ha}{ }^{-1} \mathrm{de} \mathrm{P}_{2} \mathrm{O}_{5}$, obtendo produtividade de $2375 \mathrm{~kg} \mathrm{ha}^{-1}$, resultando um incremento de $27 \% \mathrm{em}$ relação à ausência de adubação fosfatada. Os resultados nas duas safras mencionadas demonstram a alta relação do fósforo com acréscimos de produtividade em solos do cerrado.

Assim como o observado no presente trabalho, diversos autores, em trabalhos realizados no cerrado brasileiro, também encontraram resultados positivos e ajustes ao modelo quadrático para produtividade na soja em função de doses crescentes de adubação fosfatada (NETO et al., 2010; SANTOS et al., 2015; SILVA et al., 2015). Fageria, Moreira e Castro (2010), avaliando a resposta da soja em função de fertilização fosfatada em Latossolo brasileiro, concluíram que o uso de fósforo aumentou significativamente o rendimento de grãos de soja, corroborando com o resultado deste trabalho. 

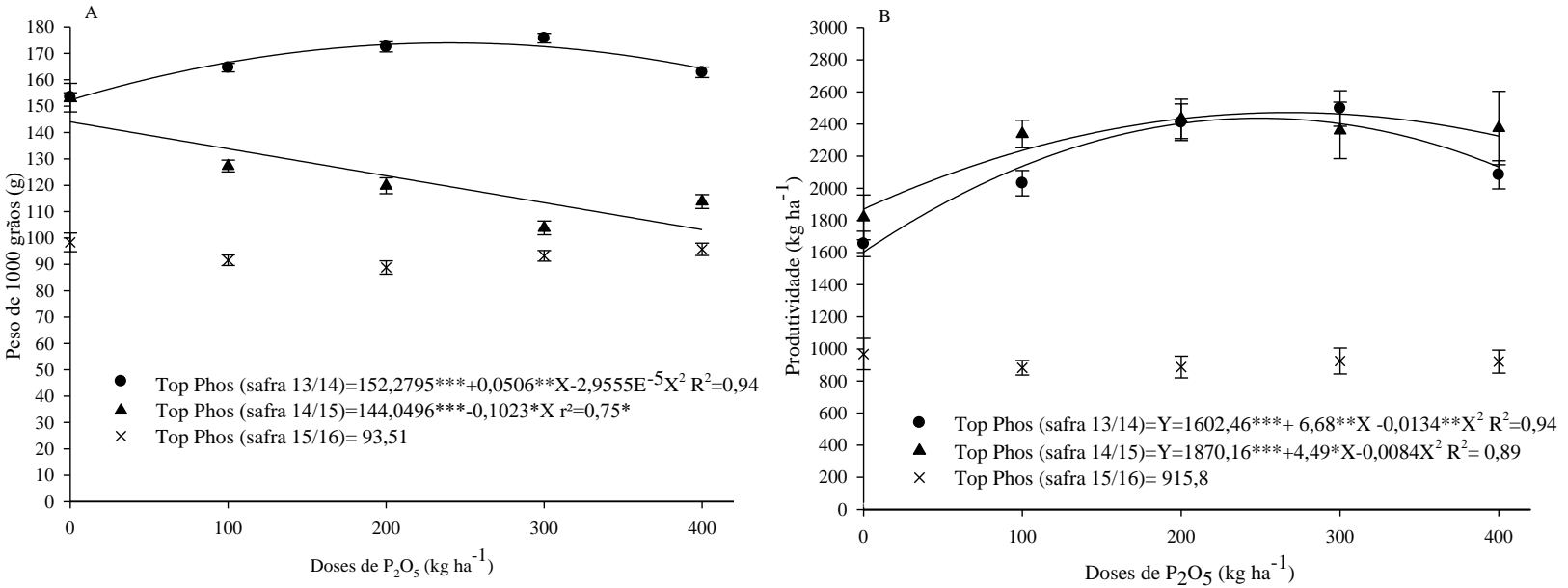

Figura 4: Peso de mil grãos (A) e Produtividade (B) de plantas de soja em função de doses do fertilizante Top-Phos ${ }^{\circledR}$ nas safras de 2013/2014, 2014/2015 e 2015/2016. Formosa do Rio Preto - BA, 2016.

Para a safra $15 / 16$ o intenso veranico ocorrido no oeste baiano prejudicou drasticamente os parâmetros avaliados, exceto a AP, justificando a baixa média de produtividade nessa safra e a não relação do $\mathrm{P}$ com a produtividade no presente experimento. Gava et al. (2015), avaliando o estresse hídrico em diferentes fases da cultura da soja, observaram que ocorrência de déficit hídrico prejudicou a altura total das plantas, número de vagens por planta, número de grãos por planta e peso de 100 grãos, afetando diretamente a produtividade. Estes autores também constataram a ocorrência de déficit hídrico apenas no enchimento de grãos representa o mesmo risco de perdas em relação à ocorrência no ciclo total.

Os resultados encontrados neste trabalho demonstram a importância da fertilização fosfatada em solos de interesse econômico para o país, pois foi possível observar expressivos incrementos na produtividade das plantas de soja, assim demonstrando a viabilidade desta prática na região do MATOPIBA.

\section{CONCLUSÕES}

Doses crescentes de adubação fosfatada tiveram influência positiva sobre os parâmetros altura de plantas, número de vagens por planta e Produtividade em solo de cerrado brasileiro.

Em condições extremas de déficit hídrico, as plantas de soja responderam apenas para o parâmetro altura de plantas. Não havendo influência dos outros parâmetros nessas condições.

Doses de adubação fosfatada não apresentam influência expressiva sobre a quantidade de grãos por vagens.

\section{REFERÊNCIAS BIBLIOGRÁFICAS}

ALVARES, C.A.; STAPE, J.L.; SENTELHAS, P.C.; GONCALVES, J. L.M.; SPAROVEK, G. Koppen's climate classification map for Brazil. Meteorologische Zeitschrift, v. 22, n. 6, p. 711-728. 2013. DOI: http://dx.doi.org/10.1127/0941-2948/2013/0507

ANDREA, M.C.S.; ROMANELLI, T.L.; MOLIN, J.P. Energy flows in lowland soybean production system in Brazil. Ciência Rural, Santa Maria, v.46, n.8, p.1395-1400, 2016. DOI: http://dx.doi.org/10.1590/0103$8478 \mathrm{cr} 20151298$

BEZERRA, M. A. F.; OLIVEIRA, F. A.; BEZERRA, F. T.C.; PEREIRA, W. E.; SILVA, S. A. Cultivation of cowpea in oxisols under the residual effect of phosphorus fertilization. Revista Caatinga, Mossoró, v. 27, n.1, p. 109-115. 2014.

BONFIM-SILVA, E. M.; GUIMARÃES, S. L.; FARIAS, L. N.; OLIVEIRA, J. R.; BOSA, C. K.; FONTENELLI, J. V. Adubação fosfatada no desenvolvimento e produção de feijão guandu em latossolo vermelho do cerrado em primeiro cultivo. Bioscience Journal, Uberlandia, v.30, p. 1380-1388. 2014.

COLOMBO, G.A.; PELUZIO, J.M.; PIRES, L.P.M.; DARONCH, D.J.; MACHADO FILHO, G.C. Phosphorus use efficiency of soybean cultivars in cerrado conditions of Tocantins, Brazil. Journal of Bioenergy and Food Science, Macapá, v.3, n.1, p.42-49. 2016. DOI: http://dx.doi.org/10.18067/jbfs.v3i1.53 
CONAB (Companhia Nacional de Abastecimento). Acompanbamento da safra brasileira. Grãos, v.4-Safra 2016/17 - Oitavo levantamento, Brasília, ISSN 23186852. 2017. p. 1-144.

EMBRAPA (Empresa Brasileira de Pesquisa Agropecuária). Centro Nacional de Pesquisa de Solos. Sistema brasileiro de classificação de solos. 3. ed. Brasília: Embrapa, 2013. 353p.

EMBRAPA (Empresa Brasileira de Pesquisa Agropecuária). Tecnologia de produção de soja região central do Brasil. Embrapa soja. ISSN 1677-8499; n,14. 2011. 255p.

FAGERIA, MOREIRA \& CASTRO. Response of Soybean to Phosphorus Fertilization in Brazilian Oxisol. Communications in Soil Science and Plant Analysis, New York, v.42, p. 2716-2723, 2011. DOI: http://dx.doi.org/10.1080/00103624.2011.622819

GAVA, R.; FRIZZONE, J. A.; SNYDER, R. L.; JOSE, J. V.; FRAGA JUNIOR, F. J.; PERBONI, A. Estresse hídrico em diferentes fases da cultura da soja. Revista Brasileira de Agricultura Irrigada, Fortaleza, v. 9, p. 349-359. 2015. DOI: http://dx.doi.org/10.7127/rbai.v9n600368

MALAVOLTA, E. Manual de nutrição mineral de plantas. São Paulo: Livro ceres, 2006. 638p.

NETO, F.; GRAVINA, G.A.; SOUZA, N.O.S.; BEZERRA, A.A.C. Adubação fosfatada na cultura da soja na microrregião do Alto Médio Gurguéia. Revista Ciência Agronômica, v. 41, n. 2, p. 266-271, 2010.

OLIVEIRA JUNIOR, A.; PROCHNOW, L.I.; KLEPKER, D. Eficiência agronômica de fosfato natural reativo na cultura da soja. Pesquisa Agropecuária Brasileira, Brasília, v.43, n.5, p.623-631, 2008.

OLIVEIRA JÚNIOR, A.; PROCHNOW, L.I.; KLEPKER, D. Soybean yield in response to application of phosphate rock associated with triple superphosphate. Scientia Agricola, Piracicaba, v.68, n.3, p.376-385, 2011.

PELUCO, R.G.; MARQUES JÚNIOR, J.; SIQUEIRA, D.S.; PEREIRA, G.T.; BARBOSA, R.S.; TEIXEIRA, D.B. Mapeamento do fósforo adsorvido por meio da cor e da suscetibilidade magnética do solo. Pesquisa Agropecuária Brasileira, Brasília, v.50, n.3, p.259-266, 2015. DOI: $\quad$ http://dx.doi.org/10.1590/S0100204X2015000300010

REINA, E.; PELUZIO, J.M.; AFFÉRRI, F.S.; SIEBENEICHLER, S.C. Análise multivariada e eficiência do uso do fósforo em soja, visando o teor de carboidratos, no estado do Tocantins. Bioscience Journal, Uberlandia, v. 30, n. 5, p. 1371-1379, 2014.
REZENDE, P. M.; GRIS, C.F.; CARVALHO, J.G.; GOMES, L.L.; BOTTINO, L. Adubação foliar. I. Épocas de aplicação de fósforo na cultura da soja. Ciência e Agrotecnologia, Lavras, v.29, n.6. p.1105-1111, 2005.

ROSOLEM, C.A. \& TAVARES, C.A. Sintomas de deficiência tardia de Fósforo em soja. Revista Brasileira de Ciência do Solo, v. 30, p. 385-389, 2006.

SANTOS, A.C.M.; CARNEIRO, J.S.S.; LEITE, R.C.; SOUZA, M.A.S.; FREITAS, G.A.; SILVA, R.R. Adubação fosfatada com fertilizante Basiduo ${ }^{\circledR}$ na cultura da soja no oeste da Bahia. Journal of Bioenergy and Food Science, Macapá, v.2, n.3, p.82-90, 2015. DOI: http://dx.doi.org/10.18607/jbfs.v2i3.25

SEDIYAMA, T.; TEIXEIRA, R. C.; REIS, M. S. Melhoramento da soja. In: BORÉM A. Melhoramento de espécies cultivadas. Viçosa: Editora UFV, 2005, p. 553-603.

SCHONINGER, E. L.; LANGE, A.; MENEGON, T. G.; CAIONE, G. Grain yield of bean as affected by phosphorus and nitrogen rates. Agrarian. Dourados, 8, 387-398. 2015.

SILVA, J. A.; OLIVEIRA, A. P.; MOURA, M. F.; SILVA, J. A.; ARAÚJO, M. A. M. Efeito residual da adubação fosfatada em três cultivos sucessivos com feijão-caupi. Revista Caatinga, Mossoró, 27, 31-38. 2014.

SILVA, R.R.; LEITE, R.C.; FREITAS, G.A.; SILVA, P.S.S.; CARNEIRO, J.S.S. Eficiência de fertilizante fosfatado na cultura da soja no cerrado baiano. Agropecuária Científica no Semiárido, v.11, n.4, p.13-22, 2015 .

ZHOU, T.; DU, Y.; AHMED, S.; LIU, T.; REN, M.; LIU, W.; YANG, W. Genotypic Differences in Phosphorus Efficiency and the Performance of Physiological Characteristics in Response to Low Phosphorus Stress of Soybean in Southwest of China. Frontiers in Plant Sciences. v. 7. pg. 1776. 2016. DOI: http://dx.doi.org/10.3389/fpls.2016.01776 